\title{
Emotional Responses to Energy Projects: Insights for Responsible Decision Making in a Sustainable Energy Transition
}

\author{
Goda Perlaviciute ${ }^{1, *}$, Linda Steg ${ }^{1}$, Nadja Contzen ${ }^{1}$ (D), Sabine Roeser ${ }^{2}$ and Nicole Huijts ${ }^{3}$ (D) \\ 1 Environmental Psychology, Faculty of Behavioural and Social Sciences, University of Groningen, \\ Groningen 9712 TS, The Netherlands; e.m.steg@rug.nl (L.S.); n.contzen@rug.nl (N.C.) \\ 2 Ethics and Philosophy of Technology Section, Department of Values, Technology and Innovation, \\ Faculty of TPM, Delft University of Technology, Delft 2628 BX, The Netherlands; S.Roeser@tudelft.nl \\ 3 Human-Technology Interaction Group, Department of Industrial Engineering \& Innovation Sciences, \\ Eindhoven University of Technology, Eindhoven 5600 MB, The Netherlands; n.m.a.huijts@tue.nl \\ * Correspondence: g.perlaviciute@rug.nl
}

Received: 31 May 2018; Accepted: 9 July 2018; Published: 19 July 2018

\begin{abstract}
Energy projects aimed at a sustainable energy transition can trigger strong negative emotions and resistance from the public. While practitioners are increasingly realising that they cannot simply ignore public emotions, they struggle with how to deal with people's emotional responses and how to secure public acceptability of sustainable energy projects. We argue that a first critical step in order to adequately address emotional responses to energy projects is to understand where these emotional responses come from. We introduce a value-based approach, which entails that different characteristics of energy projects may violate or support people's core values, which evokes emotions in people. We present a theoretical framework of the relationship between people's values, the (perceived) implications of energy projects for these values, and people's emotional responses to energy projects. We give examples from case studies in the literature to substantiate our reasoning, and we offer directions for future research. Our novel approach provides critical insights for project developers, decision makers, engineers, and scientists who aim to better understand the human dimension of a sustainable energy transition.
\end{abstract}

Keywords: emotions; public acceptability; sustainable energy transition; values

\section{Emotional Responses to Energy Projects}

To limit global climate change and its impacts, it is essential to shift toward more sustainable methods of energy use and supply. Various energy projects are being proposed, including energy sources that emit less $\mathrm{CO}_{2}$ (e.g., solar, wind energy) and technologies that prevent that already emitted $\mathrm{CO}_{2}$ gets into the atmosphere (e.g., carbon capture and storage, CCS). Such projects often face strong negative emotions and resistance from the public - for example, angry citizens demonstrating against the siting of wind turbines, a concerned public appealing against the building of hydropower dams, or enraged residents rejecting the plans for CCS facilities in their region. This clearly demonstrates that sustainable energy transition is not a purely technological endeavour; it has a prominent social dimension as it impacts on citizens and requires public support in order to be successfully realised [1-3]. Yet, actors responsible for the development of energy projects struggle with how to address people's emotional responses and increase public acceptability of sustainable energy projects. It is therefore important to understand which factors drive public emotions toward energy projects and how to address these factors in responsible decision making on a sustainable energy transition, which is the key aim of this paper. We introduce a value-based approach to explain public emotions toward energy 
projects that can help practitioners to develop energy projects that evoke less negative (and more positive) emotions from the public. In what follows, we first describe how emotions toward energy projects are currently dealt with in practise. Next, we explain the value-based approach and how it can help to better understand and address people's emotional responses toward energy projects; we provide examples from the literature to illustrate our reasoning. We then explain how our approach can contribute to responsible decision making on a sustainable energy transition. We emphasize the importance of a normative analysis to address normative ethical questions regarding different value priorities and conflicting emotions regarding energy projects. We end with a conclusion, emphasizing the added value of our approach for realising a sustainable energy transition in a way that is socially responsible, evokes positive rather than negative emotions from the public, and is socially acceptable.

\section{Current Responses to Emotions}

Practitioners, including politicians, engineers, and project managers, struggle with how to deal with people's emotional responses in an adequate way [4], as little is known about factors causing emotional responses to energy projects. As a consequence, practitioners rely on their own gut feelings when evaluating people's emotional responses, and they often come to the conclusion that people are being irrational, unreasonable, and that they overreact [4-6]. They may downplay public opinion as illegitimate if it is "clouded" by emotions, because they see emotions as inhibiting one's ability to think rationally and constructively [7]. This often leads practitioners to respond to public emotions in ineffective or even counter-effective ways.

One common response is to simply continue with a project that triggers negative public emotions, thereby neglecting these emotions. This approach typically fuels (more) public resistance and, as a result, responsible actors may need to stop the project altogether at a later stage, oftentimes after major investments have been made. For example, while Chilean authorities initially approved a contentious plan to build five mega hydropower dams in Patagonia, the project was aborted after eight years of persistent opposition from citizens, community groups, and national and international nongovernmental organisations [8]; see also internationalrivers.org.

Another response is immediately stopping projects that trigger negative emotions. Although intuitively this may seem a responsible way to accommodate public concerns, it may in fact be irresponsible. If all energy projects aimed at a sustainable energy transition get cancelled immediately once they trigger negative emotions, a sustainable energy transition will be seriously hampered. Importantly, such responses prevent the possibility to gain understanding into what evoked negative emotions and how a project could be adjusted or how new, better projects could be developed that do not elicit negative emotions and resistance [9].

When practitioners do respond to public emotions, their responses can be ineffective if they are based on inaccurate or erroneous assumptions about where these emotions come from and whether and how they can be addressed. A first assumption is that if people knew and understood the benefits of energy projects better and/or if their faulty assumptions about the costs and benefits of energy projects were corrected, they would favour these projects like project developers do [7]. For instance, when promoting wind parks, practitioners tend to emphasize how important these parks are for limiting climate change. However, this may not address people's important concerns, such as the impact on their living environment. Consequently, people may think they are not taken seriously, and their negative emotions may remain or amplify. This may, for example, be the case for persistent resistance against wind energy developments in many countries (e.g., European Platform Against Windparks, epaw.org; windnee.nl; wind-watch.org; stopthesethings.com; ventdecolere.org) [10].

Second, practitioners often assume negative emotions and resistance from local communities can be qualified as "not in my backyard" (NIMBY) responses. NIMBY implies that local citizens are being selfish and parochial, unwilling to face any personal costs from energy projects. Attributing public resistance only to NIMBY responses neglects other possible genuine concerns of local residents, such as a fair distribution of costs and benefits and the effects of energy projects on the identity and 
symbolic value of a locality $[7,11]$. Not properly addressing these concerns is likely to sustain or even augment negative emotions.

A third assumption is that negative emotions can be eliminated by providing compensations to those who may experience negative consequences. Compensations may indeed enhance perceived fairness of distribution of costs and benefits, for example when providing compensations to people living close to large-scale wind parks or biomass plants. Yet, if compensations are enforced top-down without consulting local communities, people may think that they are being manipulated or bribed to gain their support for energy projects [12], which may fuel negative emotions and resistance.

These common responses to emotions consist of trying to soothe or avoid negative emotions, but they do not address key factors that cause emotional responses. This is the main reason, we argue, why these approaches are problematic and oftentimes ineffective. If not properly addressed, negative emotions toward energy projects can be stressful to people and threaten their well-being [13]. Next, negative emotions can elicit public resistance, or there may be a reason why resistance persists, namely if emotions are not properly addressed. Indeed, emotions influence people's attitudes and behaviour [14-16], and negative emotions are associated with low public acceptability of relevant energy projects [17-19]. We define public acceptability as the extent to which people favour or disfavour an energy project [20]. The abovementioned approaches to public emotions are likely to reduce rather than to increase public acceptability and as such they may cause frustration for both citizens and project developers, induce high costs because of delays and even cancelations of energy projects, and hamper a sustainable energy transition. It is therefore in the interest of practitioners to better understand public emotions and develop new, more responsible approaches to develop and implement energy projects that evoke less negative emotions and are more socially acceptable.

We propose a novel approach to address emotional responses toward energy projects, based on understanding what causes emotions in the first place. Specifically, we argue that emotions are not "irrational" or unreasonable, but they can be seen as a form of "practical rationality", helping people to evaluate situations and to respond in an effective and adaptive way [14,21-25]. In fact, emotions have been found necessary for people to take sensible decisions in social situations. For example, patients with damages in the prefrontal cortex, which inhibit their emotional responsiveness, show socially and morally inadequate behaviour [26]. This implies that emotions may have a sensible basis and may entail good reasons for people to oppose or accept certain energy projects, which may be overlooked by practitioners [27]. Given that emotions can have a sensible basis, the next important question is what constitutes this basis, namely where emotions come from. We propose a value-based approach to explain public emotions to energy projects. Specifically, we argue that emotions are evoked by the extent to which different project characteristics are expected to violate or support people's core values. Our novel approach provides new insights that help to explain and address people's emotional responses to energy projects and thereby improve current strategies to deal with emotions and increase public acceptability of a sustainable energy transition.

\section{Value-Based Approach}

Values reflect general goals that people strive for in life [28] and reflect what is important to people in general, across time and many different situations [29,30]. People across the world endorse different values to a certain extent, but they prioritise values differently. Please note that we refer here to the values as a general individual characteristic, which are not specific to the energy projects that people are evaluating. Yet, different energy projects have different implications for people's values. Specifically, different characteristics of energy projects, for example the type of technology used, the related costs, the quality and security of energy supply, the possible health and safety hazards, the consequences for nature and the environment, the distribution of costs and benefits, and the characteristics of decision making process, can all have implications for people's values [20,31]. Energy projects may particularly have implications for four types of values: biospheric values, in which case people particularly care about protecting nature and the environment; altruistic values, which implies 
people mostly aim to safeguard the well-being of others; egoistic values, which implies safeguarding personal resources such as wealth and status; and hedonic values, which implies that people are especially seeking pleasure and comfort [20]. People differ in how strongly they endorse these values, which influences which characteristics of energy projects they consider important, and how acceptable they find different energy projects [32-34]. Yet, the role of emotions has not been addressed in these studies. We propose that the more strongly people endorse certain values, the more likely they are to respond emotionally to energy projects that have implications for these values. An energy project will elicit negative emotions when it is expected to have negative implications for one's core values, while it will elicit positive emotions when it is expected to have positive implications for one's core values. Our approach is in line with appraisal theories, stating that emotions are evoked by the aspects of objects and situations that people find particularly important [35]. Appraisal theories, however, do not consider people's individual values, and the four types of values in particular, as generic predictors of what people find important across different objects and situations and have not been applied in the energy context. The added value of our approach is that it explains which characteristics of energy projects have most impact on individuals' emotional responses to and acceptability of energy projects and why, namely because these characteristics have implications for their core values. We argue that people's emotional responses toward energy projects can be explained by implications that project characteristics have for the four types of people's values, taking into account how strongly individuals endorse these values. Below, we review concrete examples from the literature to demonstrate how the value-based approach could explain emotions evoked by energy projects.

\subsection{Project Characteristics, Values, and Emotions}

Various characteristics of energy projects and the way these projects are implemented, including physical, economic, political-institutional, and social characteristics, may have implications for people's values, which can explain emotional responses to these projects. Nuclear power for example evokes a feeling of dread in people [6], which has been linked to negative affect [36]. Nuclear power may threaten people's altruistic and biospheric values because the risks that people associate with it, such as nuclear accidents, nuclear waste, health hazards, and nuclear weapon proliferation, can be seen as threatening the society at large, future generations, and nature and the environment $[19,20,37]$. Our reasoning implies that the stronger people endorse altruistic and/or biospheric values, the more negative emotions they experience toward nuclear power. Other energy projects could have negative implications for individuals' egoistic and/or hedonic values. One example is wind energy projects, where people may be concerned about rising energy prices or intermittent energy supply [38], or visual impact and noise in case wind turbines are being placed in their vicinity [39]. Visual impact of wind turbines or transmission lines may also threaten people's biospheric and altruistic values in cases where they are seen as destroying the local (natural) character of the place [40,41].

If energy projects support people's core values, this is likely to evoke positive emotional responses. Indeed, solar power triggered mostly positive emotional responses in people [42]. Values were not measured in this study; people may consider solar power as supporting their biospheric values because it is an environmentally friendly renewable energy source. Future research could test this possibility and explore whether solar power could be seen as supporting other values too, namely egoistic, hedonic, and altruistic values. In another study, residents in the vicinity of a hydrogen fuel station felt more joy if they considered the project more beneficial for the environment and "useful for people living nearby" [43]. Positive feelings toward hydrogen fuel stations could therefore be rooted in people's biospheric values, as well as egoistic (e.g., if they consider it useful for them personally) or altruistic (e.g., if they consider it useful for other people in the community) values, respectively.

As evident from the above, energy projects typically do not only threaten or only support people's values-they have a multitude of characteristics that have negative implications for some values and positive implications for other values. This may evoke both negative and positive emotions at the same time, between people as well as within a person, depending on how strongly people endorse the 
values that are at stake. As said, nuclear power for example may be seen as threatening biospheric and altruistic values because of the environmental and societal risks, evoking negative emotions. Yet, nuclear power may be seen as supporting egoistic and hedonic values because it supplies relatively cheap and secure energy, which could evoke positive emotions [20]. Research indeed revealed that not all emotions toward nuclear power were negative-people also reported positive affective associations with nuclear energy [18]. Similarly, CCS may have positive implications for people's egoistic and hedonic values because it helps to reduce $\mathrm{CO}_{2}$ concentrations in the atmosphere without posing severe restrictions on current fossil energy use. At the same time, it may have negative implications for people's biospheric and altruistic values, because of risks such as $\mathrm{CO}_{2}$ leakage and because it may support the continued use of fossil fuels. Notably, both nuclear power and CCS potentially have not only negative but also positive implications for the same type of values, namely biospheric values. Nuclear power because its production does not emit $\mathrm{CO}_{2}$, and $\mathrm{CCS}$ because it reduces $\mathrm{CO}_{2}$ concentrations in the atmosphere. The question is: do people with strong biospheric values indeed perceive such energy projects as having negative and positive implications for their values and do they experience negative, positive, or both negative and positive emotions toward these projects? Even if nuclear energy and CCS are promoted as sustainable, people with strong biospheric values may not perceive them as such, because of the related environmental risks [44], and therefore experience more negative than positive emotions. Research has found a negative relationship between people's biospheric values and acceptability of nuclear energy [33,34]. However, these studies did not look at emotions, so we don't know whether only negative or also positive emotions were elicited and what role they played in acceptability judgements. Future research needs to study how people evaluate the implications of many different characteristics of energy projects for their core values [45] and what emotions they experience toward energy projects that simultaneously threaten and support their core values and how this influences their acceptability judgements.

The decision-making process around energy projects and the distribution of costs and benefits of energy projects across groups in society may too have implications for people's core values and evoke emotional responses. Unfair distributions of costs, risks, and benefits and unfair decision-making processes may threaten all values, namely egoistic and hedonic values (e.g., because people's personal concerns are not sufficiently addressed), altruistic values (e.g., because different groups in society face unequal costs and benefits), and biospheric values (e.g., because nature and the environment are not treated fairly). This may evoke negative emotions directly and/or elicit or strengthen emotions due to other concerns about other project characteristics, because these concerns are not properly addressed in the decision-making process (we thank an anonymous reviewer for emphasizing the substantial effects of decision making process on emotional responses to energy projects.) Some studies indeed found that perceptions of procedural and distributive fairness are related to emotional responses to energy projects. For example, the more citizens thought that the decision-making process about a hydrogen fuel station was unfair and that the distribution of costs and benefits of the hydrogen fuel station was unfair, the more negative emotions, such as anger and fear, they reported toward the hydrogen fuel station [43]. As another example regarding a wind park development in King Island, Australia, local inhabitants thought they had little say in decision making, which led to anxiety, tension, and even conflicts between community members; the project eventually got cancelled after a local opposition group took legal action [46]. In a CCS project in Barendrecht, the Netherlands, the residents thought they had little say in the decision making process, which may have explained citizens' anger and disapproval of the project and the decision-making process in a public meeting with project developers; the project got eventually cancelled [47]. Relatedly, people's negative emotions toward the CCS project in Barendrecht could have been caused/reinforced by decision makers focusing too much on technical risks and too little on the impacts that are (also) important to local people, such as the effects on their living environment and every-day life [5]. Yet, none of these studies did take individuals' values into account, so it is not yet clear which values people considered to be violated most by (perceived) unfair decision-making procedures and unfair distribution of costs and benefits, eliciting strongest 
emotions and resistance. Future studies need to address these important questions. Also, future studies could look at the extent to which the characteristics of the decision-making process elicit or strengthen emotions due to people's other concerns about other project characteristics.

\subsection{Incorporating Emotions and Values in Decision Making on Energy Projects}

Our novel approach can help us better understand people's emotional responses to energy projects and improve current strategies to address emotions as well as increase public acceptability of energy projects, which can contribute to more responsible decision making on energy projects. Rather than downgrading emotions as "irrational" and unreasonable hurdles in development and implementation of energy projects, emotions can be seen as an essential source of insight into how energy projects impact on people's core values. Neglecting emotions or explaining them in an oversimplified and inaccurate way is a missed opportunity to identify people's genuine considerations and concerns about energy projects, while such information is crucial for responsible decision making to achieve a sustainable energy transition. Our value-based approach emphasizes that both negative and positive emotions need to be considered in responsible decision making on energy projects. This is noteworthy given that negative emotions usually are given more attention in public and policy debates, probably because such negative emotions can seriously obstruct the development and implementation of energy projects. Also, the scientific literature tends to focus more on value violation than support [48]. This creates a risk that decision making focuses much more on negative than positive implications of energy projects for people's core values, while the latter may entail important reasons for implementing these projects in the first place. For example, people may protest against renewable energy projects because of (perceived) increase in energy prices, noise, or visual impact. Yet, based on their values, people may as well focus on other aspects, for example nature, the environment, and future generations, which may be supported by renewable energy projects. However, the latter may be less prominent in debate because people are not as likely to take action (e.g., protest) in support of energy projects as in opposition to them [49]. Our approach can help identify and probe both negative and positive implications of energy projects for people's different values.

The value-based approach entails that it is important to identify which characteristics of energy projects with implications for which values drive people's emotional responses, and address particularly these implications in decisions around energy projects. For example, in the case of the abovementioned hydropower project in Chile, several factors may have triggered people's negative emotions, such as concerns about Patagonia's wilderness being harmed by the dams (threatening biospheric values), concerns about negative impacts on people's own properties and/or tourism (threatening egoistic values), or considering it to be unfair that the whole country benefits from renewable energy while the local community faces all the costs and risks (threatening altruistic values). Furthermore, the decision-making process, in which public emotions and resistance were neglected for years may have evoked and/or escalated negative emotions already triggered by other project characteristics. Even if the harm to Patagonia's ecosystems could have been minimized, the hydropower project may still have elicited negative emotions if these emotions were caused by perceived negative implications for people's egoistic values. Similarly, offering financial compensations to residents may not have reduced their negative emotions toward the project if emotions were rooted in perceived negative implications for biospheric values. In both cases, negative emotions may have amplified if people thought that the Chilean government and the power company do not take their concerns seriously.

In order to adequately address people's emotional responses, it is essential to systematically investigate the roots of these emotions, in particular by looking at how different project characteristics may have implications for people's core values and which characteristics evoke emotions in people. Applying this value-based approach in practice requires assessing people's values, their perceptions of the implications of the relevant energy project for these values, and their emotional responses, via adequate instruments. Individuals' biospheric, altruistic, hedonic, and egoistic values can be measured 
by using an established value scale [50]. Perceived implications of energy projects for people's values can be measured by asking people what implications they expect energy projects to have for multiple aspects that represent these values (e.g., nature and the environment for biospheric values, equality across groups in society and future generations for altruistic values, energy prices for egoistic values, and daily comfort for hedonic values). Previous research has studied the perceived implications of energy projects for people's biospheric and egoistic values [34]; measures to test perceived implications for all four types of values need to be further developed and validated. Emotional responses can be measured by asking people how strongly they experience different emotions when thinking about a relevant energy project, including negative as well as positive emotions. For example, previous research has studied to what extent people experience anger and fear (negative emotions) and joy and pride (positive emotions) when thinking about a local hydrogen fuel station [43]. Such tools need to be further developed and validated, considering multiple emotions that people may experience toward energy projects, for example the feelings of dread [6], compassion and indignation [9], or relief and excitement. On the basis of such comprehensive assessments of the key variables, the relationship between people's values, (perceived) implications of energy projects for these values, and people's emotional responses to these energy projects can be examined. This will provide important insights in which project characteristics particularly threaten individuals' values, and hence which project characteristics could best be addressed to reduce or prevent negative emotional responses. For example, if stronger biospheric values are related to more negative emotions toward an energy project, then these negative emotions are probably caused by the (perceived) negative implications of the project for nature and the environment. Similarly, if particularly stronger egoistic values are associated with more negative emotions, these negative emotions are most likely due to perceived negative implications of energy projects for people personally, for example high energy prices.

The value-based approach helps to identify what truly concerns people and can even explain people's cognitive evaluations of energy projects. Specifically, if people experience certain emotions toward energy projects, this may influence their cognitive evaluations of these projects, a phenomenon known as the affect heuristic [51,52]. That is, positive emotions will lead them to perceive an energy project as overly positive, with many positive and few negative characteristics, while negative emotions will result in seeing the energy project as overly negative, with many negative and few positive characteristics. Such co-occurring of overly positive or negative evaluations can make it difficult to identify which characteristics of an energy project are truly important to people based on their values and caused their initial judgement. What is more, research suggests that people are rather poor judges of what motivates them. For example, when asked directly in a study, respondents said that instrumental aspects (e.g., price) and environmental aspects (e.g., $\mathrm{CO}_{2}$ emissions) are most important for them when considering adopting local renewable energy systems [53]. However, their evaluations of environmental aspects and symbolic aspects (i.e., what adoption says about them to self and others) of local renewable energy systems, and not instrumental aspects, predicted their intention to adopt such systems [53,54]. By systematically measuring and studying the relationship between people's values, the (perceived) project characteristics, and the emotional responses toward energy projects, one can identify what caused emotions in the first place.

Future research could compare the relationship between people's values, (perceived) implications of energy projects for these values, and emotional responses to energy projects across different countries and cultures. The four types of values have been distinguished in different countries and cultures [30], suggesting that these values are relevant for people in different parts of the world and could predict their emotional responses to energy projects. Yet, future research could study differences in how people across countries and cultures prioritise these values, what implications they expect from energy projects for these values, and how this in turn influences their emotional responses. There can be fundamental differences between countries in energy projects as well as in the decision making around these projects, resulting in significantly different implications of these projects for people's core values. What is more, even the same or similar energy projects can have different implications for 
people's values across different countries, for example because of the existing energy infrastructure or energy markets in these countries [55]. Studying the roots of emotional responses is crucial to get insights into how energy projects in different countries support or violate people's core values. This could contribute to insights into global energy issues such as energy poverty and spatial inequalities regarding energy use [55]. We propose that, irrespective of the possible country differences in people's value prioritisation, (perceived) implications of energy projects for these values, and people's emotional responses to energy projects, our proposed theoretical framework of the relationship between these key variables holds across countries and cultures. To test this assumption, it is important to study the proposed framework and compare the findings across different countries and cultures.

\subsection{Need for Normative Ethical Reflection}

Our reasoning posits that any type of value-biospheric, altruistic, egoistic, and hedonic —can elicit emotions in people, rather than only certain moral or so-called protected values (e.g., to protect human rights, to protect nature; [48]). This indicates that energy projects may encompass value conflicts and elicit different emotional responses between people and even within a person, depending on which values are at stake and how strongly people endorse these values. Such value-based conflicts raise important normative ethical questions about how to prioritize the different implications of energy projects for different values in a sustainable energy transition. A relevant question might be for example whether project implications for people's egoistic and hedonic values and the resulting emotions should be put at equal footing with implications for people's biospheric or altruistic values and the resulting emotions.

We propose that, first and foremost, emotions rooted in any value should be taken seriously. For all values and emotions, it could therefore be considered whether possible value threats could be overcome by (slight) adjustments of energy projects. If negative implications for certain values could be diminished without significantly threatening other values, the responsible thing to do may be to implement these changes. For example, if people experience negative emotions toward solar panels because they find them ugly, which threatens their hedonic values, this could be solved by making solar panels more aesthetically pleasing (e.g., making them colourful and artistic or making them blend in with or an integral part of the architectural design [56]). And this could be done with the people rather than deciding top-down what is most pleasing for them.

However, many value conflicts are not solved that easily. An intricacy is that a certain level of value threat may be an unavoidable feature of all energy projects, as well as of not implementing these projects. A normative ethical reflection is then necessary to give ethical grounds for whether and to what extent different values should be accommodated and how to balance them. As already discussed, renewable energy projects may support people's biospheric values (e.g., if they reduce $\mathrm{CO}_{2}$ emissions), but they may threaten people's egoistic and hedonic values (e.g., if they are expensive and intermittent), and possibly people's altruistic values (e.g., in case of perceived unfair distribution of costs, risks, and benefits). A normative ethical reflection may conclude for example that it cannot be justified that costs and risks are imposed to groups in society that are already weaker and/or marginalized $[57,58]$. Similarly, it may not be justifiable that a region that is already heavily burdened by a certain technological infrastructure is selected as a location for an energy project, if there are also suitable other locations that have been less burdened so far. A responsible solution then could involve redesigning and/or relocating the project and revising its implementation procedures in order to achieve a more fair distribution of costs, risks, and benefits, even if doing so means reducing the total amount of benefits or exposing more people to costs and risks [59]. The most relevant moral principles can differ on a case-to-case basis. While prioritization of marginalized and/or burdened groups may be necessary in one project, another project may raise questions about the type of costs, risks, and benefits that can be justified or not. For example, a normative ethical reflection may reveal that no group in society should face substantial risks for health and safety due to energy production. This reasoning can be grounded in well-established moral principles such as no harm or non-maleficence, respect 
for persons, and beneficence [60-62]. A normative ethical reflection could lead to the conclusion that there is (as yet) no way to implement an energy project in a responsible way, because doing so would seriously violate people's core values that must be protected based on ethical grounds. This could encourage attempts to develop energy projects in a new way that would do justice to emotions and values of relevant stakeholders. All in all, normative ethical reflection takes into account which values are at stake in a specific project and its decision and implementation process, and whether specific costs, risks and benefits and their distribution can be justified based on moral principles.

A key question is who should conduct such a normative analysis and whether and which stakeholders should be involved in carrying it out. Ideally, it would involve scholars and practitioners who have expertise in applied ethics, value-sensitive design, and responsible innovation. Such experts could play the role of a "values advocate" as part of a design team [63]. Alternatively, these experts could be independent ethics advisors of design teams or policymakers. None of these solutions is fail-safe, especially given the problematic issue of "ethics experts": although ethicists have advanced training in ethical theory and argumentation, they can be biased due to their own value priorities. This fact underscores the importance of continuously considering the emotions and underlying values of all different stakeholders [9] in order to avoid overlooking key concerns of different groups in the normative analysis. By explicitly including emotions and individual values, our proposed approach contributes to the existing promising strategies for participatory technology assessment, such as stakeholder involvement in design [64].

\section{Conclusions}

We sketched a novel approach to public emotional responses to energy projects. We argued that emotions are not necessarily "irrational" and unreasonable responses but may be evoked because energy projects violate or support people's core values. On the basis of examples from the literature, we theorised how different project characteristics may have implications for people's core values and therefore evoke emotional responses, which relate to public acceptability of the energy projects. We provided clear directions for applying and empirically testing the value-based approach. Specifically, this can be done by measuring people's altruistic, biospheric, hedonic, and egoistic values with an established value scale [50], (perceived) implications of energy projects for these values, and emotional responses, and next studying the relationship between individual value strength and (the strength of) emotional responses to energy projects, and the extent to which (perceived) project characteristics can explain this relationship. The value-based approach helps to identify people's genuine concerns about energy projects, thereby facilitating responsible decision making that adequately addresses these concerns. We emphasized the importance of normative ethical reflections on values and emotions in responsible decision making on energy projects. Our approach is valuable for project developers, policy makers, and scholars from different disciplines (e.g., engineering, physics, innovation sciences) in order to develop energy projects that do not trigger strong negative emotions or trigger positive emotions from the public, by means of responsible decision making. Future research could systematically study the effects of the value-based approach on public emotions and acceptability toward energy projects, across different countries and cultures, collecting lessons learned and best practices for a socially responsible and successful realisation of a sustainable energy transition. Another critical question for future research is what motivates key stakeholders in the energy transition to adopt more socially responsible approaches, such as the value-based approach, in their daily practices. This is key given the urge to scale-up and accelerate the implementation of sustainable energy projects to limit the global temperature rise to $1.5^{\circ} \mathrm{C}$. There is no time to waste on ill-managed energy projects that face costly and frustrating procedures or cancelations. As we have argued, understanding the systematic basis of emotions, as determined by project characteristics and their implications for people's core values, can make an important contribution in this. 
Author Contributions: G.P. took the lead in writing the article. L.S., N.C., S.R. and N.H. co-authored the article by providing advice and feedback during the whole writing process. The order of the authors' names represents the amount of input in the writing of the article.

Funding: This article is part of the research programme "Developing socially responsible innovations: The role of values and moral emotions" with project number 313-99-312, which is (partly) financed by the Netherlands Organisation for Scientific Research (NWO). Nicole Huijts contributed to this article while being affiliated to the Ethics and Philosophy of Technology Section of Delft University of Technology.

Acknowledgments: The authors thank Veronica R. Alfano (Department of Values, Technology and Innovation, Ethics and Philosophy of Technology Section, Faculty of TPM, Delft University of Technology) for proofreading the text and refining the language.

Conflicts of Interest: The authors declare no conflicts of interest.

\section{References}

1. Clayton, S.; Devine-Wright, P.; Swim, J.; Bonnes, M.; Steg, L.; Whitmarsh, L.; Carrico, A. Expanding the role for psychology in addressing environmental challenges. Am. Psychol. 2016, 71, 199-215. [CrossRef] [PubMed]

2. Sovacool, B.K. Energy studies need social science. Nature 2014, 511, 529. [CrossRef] [PubMed]

3. Sovacool, B.K.; Ryan, S.E.; Stern, P.C.; Janda, K.; Rochlin, G.; Spreng, D.; Pasqualetti, M.J.; Lutzenhiser, L.; Lutzenhiser, L. Integrating social science in energy research. Energy Res. Soc. Sci. 2015, 6, 95-99. [CrossRef]

4. Cass, N.; Walker, G. Emotion and rationality: The characterisation and evaluation of opposition to renewable energy projects. Emot. Space Soc. 2009, 2, 62-69. [CrossRef]

5. Pesch, U.; Correljé, A.; Cuppen, E.; Taebi, B. Energy justice and controversies: Formal and informal assessment in energy projects. Energy Policy 2017, 109, 825-834. [CrossRef]

6. Slovic, P. Perception of risk. Science 1987, 236, 280-285. [CrossRef] [PubMed]

7. Burningham, K.; Barnett, J.; Walker, G. An array of deficits: Unpacking NIMBY discourses in wind energy developers' conceptualizations of their local opponents. Soc. Nat. Resour. 2015, 28, 246-260. [CrossRef]

8. Vince, G. Dams for Patagonia. Science 2010, 329, 382-385. [CrossRef] [PubMed]

9. Roeser, S.; Pesch, U. An emotional deliberation approach to risk. Sci. Technol. Hum. Values 2016, 41, $274-297$. [CrossRef]

10. De Vries, G. How positive framing may fuel opposition to low-carbon technologies: The boomerang model. J. Lang. Soc. Psychol. 2017, 36, 28-44. [CrossRef]

11. Devine-Wright, P. Beyond NIMBYism: Towards an integrated framework for understanding public perceptions of wind energy. Wind Energy 2005, 8, 125-139. [CrossRef]

12. Ter Mors, E.; Terwel, B.W.; Daamen, D.D. The potential of host community compensation in facility siting. Int. J. Greenh. Gas Control 2012, 11, S130-S138. [CrossRef]

13. Lazarus, R.S. Psychological Stress and the Coping Process; McGraw-Hill: New York, NY, USA, 1966.

14. Haidt, J. The emotional dog and its rational tail: A social intuitionist approach to moral judgment. Psychol. Rev. 2001, 108, 814. [CrossRef] [PubMed]

15. Slovic, P. The Feeling of Risk: New Perspectives on Risk Perception; Earthscan: New York, NY, USA; Oxon, UK, 2010.

16. Taufik, D.; Bolderdijk, J.W.; Steg, L. Going green? The relative importance of feelings over calculation in driving environmental intent in the Netherlands and the United States. Energy Res. Soc. Sci. 2016, 22, 52-62. [CrossRef]

17. Huijts, N.M.A.; Molin, E.J.E.; Van Wee, B. Hydrogen fuel station acceptance: A structural equation model based on the technology acceptance framework. J. Environ. Psychol. 2014, 38, 153-166. [CrossRef]

18. Peters, E.; Slovic, P. The role of affect and worldviews as orienting dispositions in the perception and acceptance of nuclear power. J. Appl. Soc. Psychol. 1996, 26, 1427-1453. [CrossRef]

19. Truelove, H.B. Energy source perceptions and policy support: Image associations, emotional evaluations, and cognitive beliefs. Energy Policy 2012, 45, 478-489. [CrossRef]

20. Perlaviciute, G.; Steg, L. Contextual and psychological factors shaping evaluations and acceptability of energy alternatives: Integrated review and research agenda. Renew. Sustain. Energy Rev. 2014, 35, 361-381. [CrossRef]

21. Damasio, A. Descartes' Error; Putnam: New York, NY, USA, 1994. 
22. Frijda, N.H. The Emotions; Cambridge University Press: Cambridge, UK, 1986.

23. Nussbaum, M. Upheavals of Thought; Cambridge University Press: Cambridge, UK, 2001.

24. Roberts, R.C. Emotions: An Essay in Aid of Moral Psychology; Cambridge University Press: Cambridge, UK, 2003.

25. Roeser, S. Moral Emotions and Intuitions; Palgrave Macmillan: Basingstoke, UK, 2011.

26. Anderson, S.W.; Bechara, A.; Damasio, H.; Tranel, D.; Damasio, A.R. Impairment of social and moral behavior related to early damage in human prefrontal cortex. Nat. Neurosci. 1999, 2, 1032-1037. [CrossRef] [PubMed]

27. Roeser, S. Risk, Technology, and Moral Emotions; Routledge: New York, NY, USA; Oxon, UK, 2018.

28. Schwartz, S.H. Universals in the content and structure of values: Theoretical advances and empirical tests in 20 countries. In Advances in Experimental Social Psychology; Zanna, M., Ed.; Academic Press: Orlando, FL, USA, 1992; Volume 25, pp. 1-65.

29. Dietz, T. Environmental value. In Handbook of Value. Perspectives from Economics, Neuroscience, Philosophy, Psychology, and Sociology; Brosch, T., Sander, D., Eds.; Oxford University Press: Oxford, UK, 2016.

30. Steg, L.; De Groot, J.I.M. Environmental values. In The Oxford Handbook of Environmental and Conservation Psychology; Clayton, S., Ed.; Oxford University Press: New York, NY, USA, 2012; pp. 81-92.

31. Taebi, B.; Correljé, A.; Cuppen, E.; Dignum, M.; Pesch, U. Responsible innovation as an endorsement of public values: The need for interdisciplinary research. J. Responsible Innov. 2014, 1, 118-124. [CrossRef]

32. Bidwell, D. The role of values in public beliefs and attitudes toward commercial wind energy. Energy Policy 2013, 58, 189-199. [CrossRef]

33. De Groot, J.I.M.; Steg, L.; Poortinga, W. Values, perceived risks and benefits, and acceptability of nuclear energy. Risk Anal. 2013, 33, 307-317. [CrossRef] [PubMed]

34. Perlaviciute, G.; Steg, L. The influence of values on evaluations of energy alternatives. Renew. Energy 2015, 77, 259-267. [CrossRef]

35. Moors, A.; Ellsworth, P.C.; Scherer, K.R.; Frijda, N.H. Appraisal theories of emotion: State of the art and future development. Emot. Rev. 2013, 5, 119-124. [CrossRef]

36. Dohle, S.; Keller, C.; Siegrist, M. Examining the relationship between affect and implicit associations: Implications for risk perception. Risk Anal. 2010, 30, 1116-1128. [CrossRef] [PubMed]

37. Keller, C.; Visschers, V.; Siegrist, M. Affective imagery and acceptance of replacing nuclear power plants. Risk Anal. 2012, 32, 464-477. [CrossRef] [PubMed]

38. Balcombe, P.; Rigby, D.; Azapagic, A. Motivations and barriers associated with adopting microgeneration energy technologies in the UK. Renew. Sustain. Energy Rev. 2013, 22, 655-666. [CrossRef]

39. Wolsink, M. Planning of renewables schemes: Deliberative and fair decision-making on landscape issues instead of reproachful accusations of non-cooperation. Energy Policy 2007, 35, 2692-2704. [CrossRef]

40. Cotton, M.; Devine-Wright, P. Putting pylons into place: A UK case study of public perspectives on the impacts of high voltage overhead transmission lines. J. Environ. Plan. Manag. 2013, 56, 1225-1245. [CrossRef]

41. Devine-Wright, P.; Howes, Y. Disruption to place attachment and the protection of restorative environments: A wind energy case study. J. Environ. Psychol. 2010, 30, 271-280. [CrossRef]

42. Sütterlin, B.; Siegrist, M. Public acceptance of renewable energy technologies from an abstract versus concrete perspective and the positive imagery of solar power. Energy Policy 2017, 106, 356-366. [CrossRef]

43. Huijts, N.M.A. The emotional dimensions of energy projects: Anger, fear, joy and pride about the first hydrogen fuel station in the Netherlands. Energy Res. Soc. Sci. 2018, 44, 138-145. [CrossRef]

44. Perlaviciute, G.; Steg, L.; Hoekstra, E.J. Is gas perceived as sustainable? Insights from value-driven evaluations in the Netherlands. Energy Res. Soc. Sci. 2016, 20, 55-62. [CrossRef]

45. Demski, C.; Spence, A.; Pidgeon, N. Effects of exemplar scenarios on public preferences for energy futures using the my2050 scenario-building tool. Nat. Energy 2017, 2, 17027. [CrossRef]

46. Colvin, R.M.; Witt, G.B.; Lacey, J. How wind became a four-letter word: Lessons for community engagement from a wind energy conflict in King Island, Australia. Energy Policy 2016, 98, 483-494. [CrossRef]

47. Terwel, B.W.; ter Mors, E.; Daamen, D.D. It's not only about safety: Beliefs and attitudes of 811 local residents regarding a CCS project in Barendrecht. Int. J. Greenh. Gas Control 2012, 9, 41-51. [CrossRef]

48. Baron, J.; Spranca, M. Protected values. Organ. Behav. Hum. Decis. Process. 1997, 70, 1-16. [CrossRef]

49. De Groot, J.I.M.; Steg, L. Morality and nuclear energy: Perceptions of risks and benefits, personal norms, and willingness to take action related to nuclear energy. Risk Anal. 2010, 30, 1363-1373. [CrossRef] [PubMed] 
50. Steg, L.; Perlaviciute, G.; Van der Werff, E.; Lurvink, J. The significance of hedonic values for environmentally relevant attitudes, preferences, and actions. Environ. Behav. 2014, 46, 163-192. [CrossRef]

51. Finucane, M.L.; Alhakami, A.; Slovic, P.; Johnson, S.M. The affect heuristic in judgments of risks and benefits. J. Behav. Decis. Mak. 2000, 13, 1-17. [CrossRef]

52. Slovic, P.; Finucane, M.L.; Peters, E.; MacGregor, D.G. The affect heuristic. Eur. J. Oper. Res. 2007, 177, 1333-1352. [CrossRef]

53. Noppers, E.H.; Keizer, K.; Bolderdijk, J.W.; Steg, L. The adoption of sustainable innovations: Driven by symbolic and environmental motives. Glob. Environ. Chang. 2014, 25, 52-62. [CrossRef]

54. Korcaj, L.; Hahnel, U.J.; Spada, H. Intentions to adopt photovoltaic systems depend on homeowners' expected personal gains and behavior of peers. Renew. Energy 2015, 75, 407-415. [CrossRef]

55. Bouzarovski, S.; Simcock, N. Spatializing energy justice. Energy Policy 2017, 107, 640-648. [CrossRef]

56. Roeser, S. Aesthetics as a risk factor in designing architecture. In Ethics, Design and Planning of the Built Environment; Basta, C., Moroni, S., Eds.; Springer: Dordrecht, The Netherlands, 2013; Volume 12, pp. $93-105$.

57. Rawls, J. A Theory of Justice; Harvard University Press: Cambridge, MA, USA, 1971.

58. Basta, C. Risk and spatial planning. In Handbook of Risk Theory: Epistemology, Decision Theory, Ethics, and Social Implications of Risk; Roeser, S., Hillerbrand, R., Peterson, M., Sandin, P., Eds.; Springer: Berlin, Germany, 2012; pp. 265-294.

59. Shrader-Frechette, K. Environmental Justice: Creating Equality, Reclaiming Democracy; Oxford University Press: Oxford, UK, 2002.

60. Kant, I. Groundwork of the Metaphysic of Morals; Paton, H.J., Ed.; Harper and Row: New York, NY, USA, 1964.

61. Ross, W.D. The Right and the Good; The Clarendon Press: Oxford, UK, 1967.

62. Mill, J.S. On Liberty; Penguin: Harmondsworth, UK, 1985.

63. Manders-Huits, N.; Zimmer, M. Values and pragmatic action: The challenges of introducing ethical intelligence in technical design communities. Int. Rev. Inf. Ethics 2009, 10, 37-45.

64. Van den Hoven, J.; Vermaas, P.; van de Poel, I. (Eds.) Handbook of Ethics, Values, and Technological Design; Springer: Dordrecht, The Netherlands, 2015.

(C) 2018 by the authors. Licensee MDPI, Basel, Switzerland. This article is an open access article distributed under the terms and conditions of the Creative Commons Attribution (CC BY) license (http:/ / creativecommons.org/licenses/by/4.0/). 